TITLE:

\title{
Genetic and phenotypic characterization of a Japanese wild-derived DOB/Oda rat strain.
}

\section{AUTHOR(S):}

Kuramoto, Takashi; Inoue, Satoko; Neoda, Yuki; Yamasaki, Ken-ichi; Hashimoto, Ryoko; Mashimo, Tomoji; Oda, Sen-ichi; Serikawa, Tadao

\section{CITATION:}

Kuramoto, Takashi ... [et al]. Genetic and phenotypic characterization of a Japanese wildderived DOB/Oda rat strain.. Mammalian genome 2013, 24(7-8): 303-308

\section{ISSUE DATE:}

2013-07-30

URL:

http://hdl.handle.net/2433/193693

\section{RIGHT:}

The final publication is available at Springer via http://dx.doi.org/10.1007/s00335-0139465-Z.; この論文は出版社版でありません。引用の際には出版社版をご確認ご利用くだ さい。; This is not the published version. Please cite only the published version. 


\section{Genetic and phenotypic characterization of a Japanese wild-derived DOB/Oda rat strain}

Takashi Kuramoto $^{1}$, Satoko Inoue ${ }^{1}$, Yuki Neoda ${ }^{1}$, Ken-ichi Yamasaki ${ }^{1}$, Ryoko

Hashimoto $^{1}$, Tomoji Mashimo ${ }^{1}$, Sen-ichi Oda ${ }^{2,3}$, Tadao Serikawa ${ }^{1}$

${ }^{1}$ Institute of Laboratory Animals, Graduate School of Medicine, Kyoto University,

Yoshidakonoe-cho, Sakyo-ku, Kyoto 606-8501, Japan.

${ }^{2}$ Laboratory of Animal Management and Resources, Graduate School of Bioagricultural

Sciences, Nagoya University, Furo-cho, Chigusa-ku, Nagoya 464-8601, Japan

${ }^{3}$ Laboratory of Animal Management \& Resources, Department of Zoology, Faculty of

Science, Okayama University of Science, Okayama 700-0005, Japan 
Correspondence to:

Takashi Kuramoto, PhD

Institute of Laboratory Animals, Graduate School of Medicine, Kyoto University,

Yoshidakonoe-cho, Sakyo-ku, Kyoto 606-8501, Japan

Tel: +81-75-753-4494

Fax: +81-75-753-4409

E-mail: tkuramot@anim.med.kyoto-u.ac.jp

\section{Running head}

Japanese wild-derived DOB/Oda rat strain 


\section{Abstract}

Wild-derived rat strains can provide novel genome resources that are not available in standard laboratory strains. Genetic backgrounds of wild-derived strains can facilitate effective genetic linkage analyses and often modulate the expression of mutant phenotypes. Here we describe the development and characterization of a new inbred rat strain DOB/Oda from wild rats (Rattus norvegicus) captured in Shitara, Aichi, Japan. Phenotype analysis of 109 parameters revealed that the DOB/Oda rats had small body weight, preference for darkness, and high locomotor activity compared with the rat strains in the National Bio Resource Project for the Rat (NBRP-Rat) database. Genome analysis with 357 SSLP markers identified DOB/Oda-specific alleles in 70 markers. Percentage of SSLP markers that showed polymorphism between the DOB/Oda strain and any of 132 laboratory strains from NBRP-Rat varied from $89 \%$ to 95\%. The polymorphic rate (average of the values of the percentage) for the DOB/Oda strain was 91.6\%, much higher than the rates for available wild-derived strains such as the Brown Norway rat. A phylogenic tree constructed with DOB/Oda and all the strains in NBRP-Rat, showed that the DOB/Oda strain localized within the wild rat groups, apparently separate from the laboratory strains. Together, these findings indicated that the DOB/Oda rat has a unique genome that is not available in the laboratory strains. 
Therefore, the new DOB/Oda strain will provide an important genome resource that will be useful for designing genetic experiments and for the discovery of genes that modulate mutant phenotypes. 


\section{Introduction}

There has been an extraordinary increase in rat genomic resources over the past decade.

Rat genome sequences and genetic markers are now available and new methodologies for high-throughput genotyping and expression profiling have been developed (Aitman et al. 2008). In addition, database services that integrate genomic information and provide tools for data mining and analysis have been established (Dwinell et al. 2009). These infrastructure developments have allowed disease genes, not only for monogenic traits but also for more complex traits, to be positionally cloned (Aitman et al. 2008; Aitman et al. 1999; Kuramoto et al. 2011).

Recently, gene knockout rat models have been generated using technologies such as embryonic stem cells, zinc-finger nuclease (ZFN), and transcription activator-like effector nuclease (TALEN) (Kawamata and Ochiya 2010; Mashimo et al. 2010; Tesson et al.). These technologies are likely to accelerate the generation of gene knockout rats for disease models and for functional annotation (Jacob et al. 2010). The rat model is an excellent experimental system in which to study genotype-phenotype correlations in both forward and reverse genetic approaches.

It is well known that rat mutant or disease phenotypes are often altered when the genetic 
background of the causative gene underlying the phenotype is changed (Kuramoto et al. 1998; O'Meara et al. 2012; Yokoi et al. 2007). Thus, rat strains that share common mutations with different genetic backgrounds are good resources that can be used to find other causative genes underlying a mutant phenotype as well as modifier genes of the phenotype. Because gene disruption with the ZFN or TALEN technologies can be applied to the majority of available rat strains, it is expected that a repertoire of inbred strains with a particular mutation can be developed much easier than with the breeding of traditional congenic strains.

To identify effectively the genes that modulate a mutant phenotype, a rat strain with a genetic background that is very different from that of the commonly used laboratory strains is required. Because most available rat strains are derived from or are descendants of Wistar albino rats (Kuramoto et al. 2012), captured wild rats are considered as a good genetic source of genes that are not available in the laboratory strains.

The Brown Norway (BN) rat was the first wild-derived strain. It was derived from wild rats captured in the vicinity of Philadelphia, USA and various BN substrains are now available. One of the substrains was used to generate the draft sequence of the rat 
genome (Gibbs et al. 2004). Mitake rats were derived from a cross between wild rats captured in Mitake, Gifu, Japan (Ohno et al. 1994). Five strains MITA, MITB, MITC, MITD, and MITE, were developed, but they are all now extinct.

Several rat strains have been developed from hybrids obtained from crosses between laboratory rats and wild rats; they include Long-Evans (LE), Ishibashi (IS), and NIG-III rats. The LE rats are descendants of a cross (made in about 1915) between several white female Wistar rats and a wild grey male caught in Berkeley, USA (Bennett 1991). The IS rats are descendants of a cross (made in about 1975) between female Wistar rats and wild grey male rats caught in the Azabu University, Sagamihara, Kanagawa, Japan. The NIG-III rats are descendants of a cross (made in 1956) between Castle's black rats and a wild rat trapped in Mishima, Shizuoka, Japan.

To date, the BN is the only pure wild-derived strain that is available. The polymorphic rate for 357 simple sequence length polymorphism (SSLP) markers between the BN strain and any other strain ranges from 78\% to 92\% (Mashimo et al. 2006), which is not higher than the rate for the intra-species wild-derived mouse strains (Abe et al. 2004). Thus, to expand the rat genetic resources it is important to develop new wild-derived rat strains. 
In this study, we describe the development of the DOB/Oda rat strain from wild-captured rats (Rattus norvegicus) and examine their genetic and phenotypic characteristics. 


\section{Materials and methods}

\section{Capture of wild rats}

To capture wild rats ( $R$. norvegicus), we set rat traps in the goat house of the Experimental Station of Highland Animal Production (present name, Shitara Field), Graduate School of Bioagricultural Sciences, Nagoya University, Japan in February 2000. This institute is located in Shitara-cho, Aichi Prefecture, Japan, about $70 \mathrm{~km}$ east of Nagoya.

\section{Development of the DOB/Oda rat strain}

We crossed three males to four females of the wild-captured rats and obtained F1 hybrids in March 2000. Brother-sister mating with F1 hybrids was started to establish an inbred strain, tentatively named DOB after “dobu-nezumi”, a Japanese word which means the rat. At the F14 generation, the microbiological cleaning of the DOB strain was carried out by Caesarean section in the Central Institute for Experimental Animals, Kawasaki, Japan in June 2006. The colony of DOB rats (F15) was transferred to the Institute of Laboratory Animals, Graduate School of Medicine, Kyoto University in October 2007. The brother-sister mating was undertaken at every generation during the inbreeding process. Inbreeding reached the F20 generation in June 2009 and the inbred 
strain DOB/Oda was established. The DOB/Oda shows enough tameness, so we can touch and handle them without protection of our hands from their aggression. In December 2012, the inbreeding generation of the DOB/Oda strain was F27. A history of the development of the DOB/Oda strain is summarized in Fig. 1.

\section{Breeding performance}

To maintain the DOB/Oda rat strain, the routine mating of brother-sister pairs at 2 months of age was undertaken. The rats were kept in a 14h-10h light-dark cycle, at $25 \pm$ $2^{\circ} \mathrm{C}$ and $50 \pm 10 \%$ humidity and fed a standard diet (F2, Funabashi, Japan) and tap water. At each generation, the number of paired rats and the number of weaned offspring were recorded. As references, the breeding performances of the F344/Stm and LE/Stm were examined.

\section{Phenotyping}

The F20 generation of male $(n=6)$ and female $(n=6)$ DOB/Oda rats at eight weeks of age were examined for 109 phenotypic parameters as described previously (Mashimo et al. 2005). The parameters belonged to seven categories: functional observational battery (neurobehavioral), behavior studies, blood pressure, biochemical blood tests, hematology, urology, and anatomy. 


\section{Genetic profile}

Genetic profiles of the DOB/Oda rats (F28 generation) were made using the 357 SSLP markers reported previously (Mashimo et al. 2006). As reference DNA from wild rats, we used the DNA from three wild-derived Mitake strains (MITB, MITC, and MITE) (Ohno et al. 1994), six rats captured in Germany (B6, G3, HR1, HR2, RU4, and RU5) (Voigt et al. 2000), four rats captured in Xian, China, and six rats captured in Obihiro, Hokkaido, Japan. The polymorphic rate for the DOB/Oda strain was calculated as follows. Frist, the percentage of the SSLP markers that showed polymorphism between the DOB/Oda and any of 132 laboratory rat strains from the NBRP-Rat was obtained. Then, the average of the values of the percentage was calculated. This value was defined as the polymorphic rate for the DOB/Oda strain. Such procedure was made for each strain.

\section{Phylogenic tree}

A phylogenic tree for the DOB/Oda rat and other strains from the NBRP-Rat database was obtained using a heuristic search for maximum parsimony implemented in the PAUP 4.0b10 as described previously (Mashimo et al. 2006). TreeView software was used to display the radial tree. 


\section{Results}

\section{Breeding performance of the DOB/Oda rats}

We obtained 650 weaned offspring from 141 mated pairs from the F20 to F30 generations of DOB/Oda rats. Some females failed to become pregnant and some killed their offspring. The average number of weaned rats from a brother-sister mating was 4.7 \pm 0.8 . This value was not significantly different from the value for the LE/Stm rats (5.6 $\pm 1.5)$, but was significantly lower than the value for the F344/Stm rats $(12.1 \pm 0.9)$. This finding indicated that the breeding performance the DOB/Oda was relatively low, but it was still sufficient to obtain enough progeny to maintain the DOB/Oda rats as an inbred strain.

\section{Phenotypic characteristics of the DOB/Oda rats}

The mean values of each phenotypic parameter obtained for the DOB/Oda rats were compared with the same parameters for the rat strains in the NBRP-Rat database (165 strains for male and 37 strains for female). The 109 parameters consist of 76 quantitative and 33 qualitative measurements. For the quantitative phenotypic parameters, the strains were ranked according to the value of each parameter, and a "strain ranking” for a selected parameter was obtained. All the data for the DOB/Oda 
rats are available from the phenome project pages on the NBRP-Rat web site (http://www.anim.med.kyoto-u.ac.jp/nbr/phenome.aspx). Here, we focused on the parameters with the highest or lowest values in the strain rankings.

The most striking phenotype of the DOB/Oda rats was low body weight (Table 1). At 5, 6 , and 10 weeks of age, the female DOB/Oda rats had the lowest body weight among the 38 female strains (the 37 strains from NBRP-Rat plus the DOB/Oda strain). At 10 weeks of age, the male DOB/Oda rats had the lowest body weight among the 166 male strains (the 165 strains from NBRP-Rat plus the DOB/Oda strain), although at 6 weeks, their body weight was the second lowest.

At 9 weeks of age, the male DOB/Oda rats had the highest heart rate among the 166 strains and female DOB/Oda rats had the third highest heart rate among the 38 strains (Table 1). For the 30-min locomotor activity, female DOB/Oda rats were ranked the highest and male rats was ranked 13th among the other male strains (Table 1).

In a step-through-type passive avoidance test, we measured the "training time" for which the rats stayed in the light box; rats were exposed to an 8-mA electric foot shock when they entered the dark box. After 24 hours, we measured the "retention time" of the trained rats. Male DOB/Oda rats had the lowest training time among the 166 strains and 
the female rats had the second lowest training time among the 38 strains (Table 1).

Although the retention time of the trained male DOB/Oda rats was more than 300 seconds, that of female rats was $49.0 \pm 33.4$ seconds, which was the lowest ranked times among the examined 38 strains.

\section{Genetic profile of the DOB/Oda rats}

We used 357 SSLP markers to build a genetic profile of the DOB/Oda strain and identified novel alleles that were specific to the DOB/Oda strain in 70 (19.6\%) of the SSLP markers.

Percentage of SSLP markers that show polymorphism between DOB rat strain and any of 132 laboratory rat strains from the NBRP-Rat database varied from 89\% for DMY (demyelination) to $95 \%$ for ICR (Ihara cataract rat) strains, with the polymorphic rate (an average of the values of the percentage) of 91.6 (Table 2). This value is very similar to the rates reported for the Mitake strains, although these strains are now extinct, and higher than the polymorphic rates for the wild-derived laboratory rat strains, BN, IS, and NIG-III strains.

\section{Phylogenic tree including the DOB/Oda rats}

Using the genetic profile derived using the 357 SSLP marker set, we constructed a 
phylogenic tree that included 132 laboratory rat strains, the DOB/Oda strain, three Mitake strains, six wild rats captured in Obihiro, Japan, four wild rats captured in Xian, China, and six wild rats captured in Germany (Fig. 2). The laboratory rat strains formed a large cluster, while the wild rat strains were grouped according to the place where they were captured and variations among the groups were large. Of the 132 laboratory rat strains, the BN strains clustered closest to the wild rat groups. The DOB/Oda strain was localized within the wild rat groups, apparently separate from the existing laboratory strains. 


\section{Discussion}

The DOB/Oda rats showed several unique phenotypes. First, both sexes had the lowest body weights among the examined strains. Although food intake was not determined, other environmental factors during the experiments were constant. Thus, it is likely that low body weight is determined genetically in the DOB/Oda rat.

Second, the DOB/Oda rats showed strikingly short stay times in the light box in the training trials of the passive avoidance test. Rats instinctively prefer darkened areas to illuminated areas. Antianxiety agents such as the benzodiazepines have been shown to increase durations of stay and exploratory behavior in the illuminated area, while anxiety agent decrease them (Chaouloff et al. 1997). Thus, the DOB/Oda strain appeared to feel more anxiety than other laboratory strains when exposed to a new environment.

Last, the DOB/Oda rats showed comparatively high locomotor activity in the open field test, suggesting high spontaneous motor activity. Together, these findings suggest that the DOB/Oda rats may have inherited some of the characteristics of wild rats, including low body weight, high activity, and preference for darkness. 
With such unique phenotypes, the DOB/Oda rats could be used in research fields such as physiology, pharmacology, neurology, and behavioral genetics.

The DOB rats also showed some unique genetic features. Among the 357 SSLP markers we examined, number of markers that showed polymorphism between the DOB/Oda and any of 168 laboratory strains varied 314 (88\%) to 340 (95\%). As for the BN rat, which was derived from wild-captured rats, number of SSLP markers that showed polymorphism against any of 168 strains varied 250 (70 \%) to 335 (94\%). The 168 laboratory strains included almost all the available strains; however, two recently-established strains of wild-derived rats artificially selected for tameness and defensive aggression towards humans are not included (Albert et al. 2008). Although we have not yet analyzed the genome of these strains, it is likely that, like the DOB rats, they too will show remarkably high polymorphic rate compared with the rates for the other laboratory rat strains. We have shown that the DOB/Oda strain has enough breeding performance to be maintained as an inbred strain; therefore, we propose that the DOB/Oda strain can become a prominent bioresource for genetic linkage analyses and for the identification of the causative genes in rat models of human diseases. Recently, we identified the causative gene for cataract development using a DOB/Oda 
rat as a parental strain in the linkage analysis (Watanabe et al. 2012).

It was suggested that the ZFN and TALEN technologies could be powerful tools to disrupt gene functions in rats (Mashimo et al. 2010). To make gene knockout rats, the RNAs that encode ZFN and TALEN, which recognize and digest the specific site of a target gene, are microinjected to rat embryos. When these technologies are applied to the embryos of different rat strains, a repertoire of knockout rat strains in which the target gene is disrupted against the different genetic backgrounds, are efficiently generated. Because the DOB/Oda strain has a genetic background that is extremely different from other laboratory strains, it could contribute to the identification of modifiers of the knockout gene.

In summary, the genome of the wild-derived DOB/Oda rat strain is apparently different from the genomes of the existing laboratory strains. Thus, the DOB/Oda rat will be useful as a parental strain in genetic linkage analyses and will provide an important genome resource for use in the discovery of genes that modulate mutant phenotypes. 


\section{Acknowledgements}

We thank Drs Zhang and Ishii for providing tissues from wild rats captured in Xian,

China and Obihiro, Japan respectively, and Drs. K. Mekata and A. Natsume for breeding several generations from the wild rats captured in the Shitara Field, Nagoya University Japan. This work was supported by the National BioResource Project (NBRP) in Japan. The DOB/Oda rat has been deposited in the NBRP-Rat in Japan and is available from NBRP (http://www.anim.med.kyoto-u.ac.jp/nbr). 


\section{References}

Abe K, Noguchi H, Tagawa K, Yuzuriha M, Toyoda A et al. (2004) Contribution of Asian mouse subspecies Mus musculus molossinus to genomic constitution of strain C57BL/6J, as defined by BAC-end sequence-SNP analysis. Genome Res 14:2439-2447 Aitman TJ, Critser JK, Cuppen E, Dominiczak A, Fernandez-Suarez XM et al. (2008) Progress and prospects in rat genetics: a community view. Nat Genet 40:516-522

Aitman TJ, Glazier AM, Wallace CA, Cooper LD, Norsworthy PJ et al. (1999) Identification of Cd36 (Fat) as an insulin-resistance gene causing defective fatty acid and glucose metabolism in hypertensive rats. Nat Genet 21:76-83

Albert FW, Shchepina O, Winter C, Rompler H, Teupser D et al. (2008) Phenotypic differences in behavior, physiology and neurochemistry between rats selected for tameness and for defensive aggression towards humans. Horm Behav 53:413-421

Bennett LL (1991) The Long and Evans monograph on the estrous cycle in the rat. Endocrinology 129:2812-2814

Chaouloff F, Durand M, Mormede P (1997) Anxiety- and activity-related effects of diazepam and chlordiazepoxide in the rat light/dark and dark/light tests. Behav Brain 
Res 85:27-35

Dwinell MR, Worthey EA, Shimoyama M, Bakir-Gungor B, DePons J et al. (2009) The

Rat Genome Database 2009: variation, ontologies and pathways. Nucleic Acids Res 37:D744-749

Gibbs RA, Weinstock GM, Metzker ML, Muzny DM, Sodergren EJ et al. (2004)

Genome sequence of the Brown Norway rat yields insights into mammalian evolution.

Nature 428:493-521

Jacob HJ, Lazar J, Dwinell MR, Moreno C, Geurts AM (2010) Gene targeting in the rat: advances and opportunities. Trends in Genetics 26:510-518

Kawamata M, Ochiya T (2010) Generation of genetically modified rats from embryonic stem cells. Proc Natl Acad Sci U S A 107:14223-14228

Kuramoto T, Kuwamura M, Tokuda S, Izawa T, Nakane Y et al. (2011) A mutation in the gene encoding mitochondrial $\mathrm{Mg}^{2+}$ channel MRS2 results in demyelination in the rat. PLoS Genet 7:e1001262

Kuramoto T, Nakanishi S, Ochiai M, Nakagama H, Voigt B et al. (2012) Origins of albino and hooded rats: implications from molecular genetic analysis across modern 
laboratory rat strains. PLoS One 7:e43059

Kuramoto T, Yamasaki K, Kondo A, Nakajima K, Yamada M et al. (1998) Production of WTC.ZI-zi rat congenic strain and its pathological and genetic analyses. Exp Anim $47: 75-81$

Mashimo T, Takizawa A, Voigt B, Yoshimi K, Hiai H et al. (2010) Generation of knockout rats with X-linked severe combined immunodeficiency (X-SCID) using zinc-finger nucleases. PLoS One 5:e8870

Mashimo T, Voigt B, Kuramoto T, Serikawa T (2005) Rat Phenome Project: the untapped potential of existing rat strains. J Appl Physiol 98:371-379

Mashimo T, Voigt B, Tsurumi T, Naoi K, Nakanishi S et al. (2006) A set of highly informative rat simple sequence length polymorphism (SSLP) markers and genetically defined rat strains. BMC Genet 7:19

O'Meara CC, Hoffman M, Sweeney WE, Jr., Tsaih SW, Xiao B et al. (2012) Role of genetic modifiers in an orthologous rat model of ARPKD. Physiol Genomics $44: 741-753$

Ohno K, Niwa Y, Kato S, Kondo K, Oda S et al. (1994) Establishment of new inbred 
strain derived from Japanese wild rats (Rattus norvegicus). Exp. Anim. 43:251-255

Tesson L, Usal C, Menoret S, Leung E, Niles BJ et al. Knockout rats generated by embryo microinjection of TALENs. Nat. Biotechnol. 29:695-696

Voigt B, Kitada K, Kloting I, Serikawa T (2000) Genetic comparison between laboratory rats and Japanese and German wild rats. Mamm. Genome 11:789-790

Watanabe K, Wada K, Ohashi T, Okubo S, Takekuma K et al. (2012) A 5-bp insertion in Mip causes recessive congenital cataract in KFRS4/Kyo rats. PLoS One 7:e50737

Yokoi N, Hayashi C, Fujiwara Y, Wang HY, Seino S (2007) Genetic reconstitution of autoimmune type 1 diabetes with two major susceptibility genes in the rat. Diabetes $56: 506-512$ 


\section{Tables}

Table 1 Parameters for which DOB/Oda rats had the highest or lowest values among the strains characterized by the NBRP-Rat

\begin{tabular}{|c|c|c|c|c|c|c|}
\hline \multirow{4}{*}{ Parameter $^{\mathrm{a}}$} & \multicolumn{3}{|c|}{ Male } & \multicolumn{3}{|c|}{ Female } \\
\hline & All rat strains & & & All rat strains & & \\
\hline & examined & DOB/Oda & Ranking ${ }^{\mathrm{b}}$ & examined & DOB/Oda & Ranking ${ }^{b}$ \\
\hline & $(n=166)$ & & & $(n=38)$ & & \\
\hline Body weight at 5 weeks of age (g) & $103.7 \pm 23.2$ & $72.9 \pm 0.9$ & 153 & $100.0 \pm 23.2$ & $57.8 \pm 3.1$ & 38 \\
\hline Body weight at 6 weeks of age (g) & $142.2 \pm 30.7$ & $84.9 \pm 2.5$ & 165 & $118.5 \pm 30.2$ & $63.2 \pm 2.7$ & 38 \\
\hline Body weight at 10 weeks of age (g) & $248.5 \pm 54.7$ & $132.8 \pm 8.4$ & 166 & $164.9 \pm 40.6$ & $79.3 \pm 5.1$ & 38 \\
\hline Hear rate (beats/min) & $437.8 \pm 42.6$ & $539 \pm 104$ & 1 & $472.6 \pm 37$ & $532 \pm 71$ & 3 \\
\hline Locomotor activity for $30 \mathrm{~min}$ & $6646 \pm 1301$ & $8373 \pm 741$ & 13 & $6362 \pm 1389$ & $866 \pm 1224$ & 1 \\
\hline
\end{tabular}


${ }^{\text {a}}$ Data obtained from the NBRP-Rat web site (http://www.anim.med.kyoto-u.ac.jp/nbr/phenome/).

${ }^{\mathrm{b}}$ Ranked in descending order. 
Table 2 Polymorphic rates for wild-derived rat strains

\begin{tabular}{cc}
\hline Strain $^{\mathrm{a}}$ & Polymorphic rates $(\%)^{\mathrm{b}}$ \\
\hline DOB/Oda & 91.6 \\
MITB (extinct) & 90.7 \\
MITC (extinct) & 90.7 \\
MITE (extinct) & 92.0 \\
BN & 80.3 \\
IS/Kyo & 84.0 \\
NIG-III/Hok & 76.3 \\
\hline
\end{tabular}

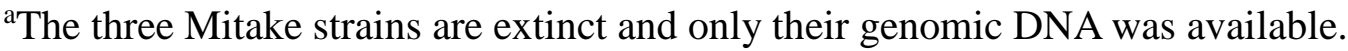

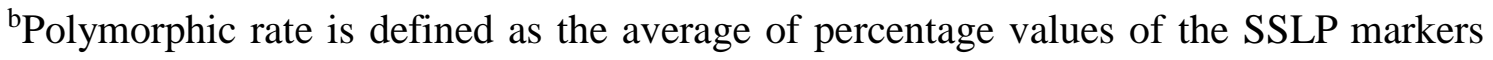
that show polymorphism between the corresponding strain and the remaining strains. Because the BN, IS, and NIG-III strains were included in the 132 laboratory strains, the polymorphic rates were calculated against the other 131 strains. 


\section{Figure legends}

Fig. 1 Development of the DOB/Oda strain

A History of the development of the DOB/Oda strain. In 2000, several wild rats were captured in the Shitara area of Aichi, Japan. These rats are the ancestors of the DOB/Oda inbred strain. Following microbiological cleaning in 2006, the F14 breeding colony was transferred to Kyoto University where it was maintained in a specific pathogen-free condition. In 2009, the inbreeding generation was F20 and the DOB/Oda inbred strain was established. B External appearance of the DOB/Oda rat at 10 weeks of age.

Fig. 2 Phylogenic tree including the DOB/Oda rats

This phylogenic tree includes the DOB/Oda strain, 19 wild-captured rats, and 132 laboratory strains. To make it easy to see names of strains, substrain names were omitted in ACI, BN, F344, and SHR substrains. The DOB/Oda stain localized within the wild rat groups, apparently separate from the existing laboratory rat strains. 
\begin{tabular}{l|cl} 
A & P & wild rats were captured in Shitara, Aichi, Japan \\
$2000 / 3$ & F1 & \\
$2006 / 6$ & F14 & microbiological cleaning \\
$2007 / 7$ & F15 & colony was transferred to Kyoto University \\
$2009 / 6$ & F20 & inbreeding reached to 20 generations \\
$2012 / 12$ & F27 & inbreeding reached to 27 generations
\end{tabular}

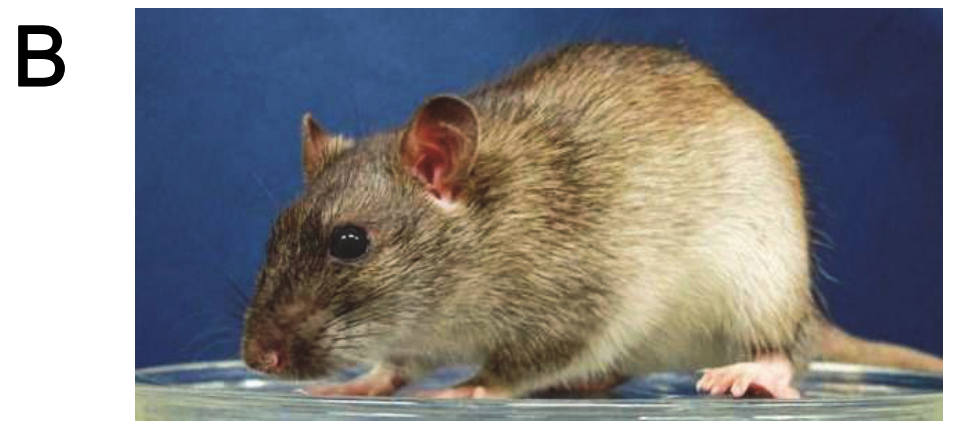




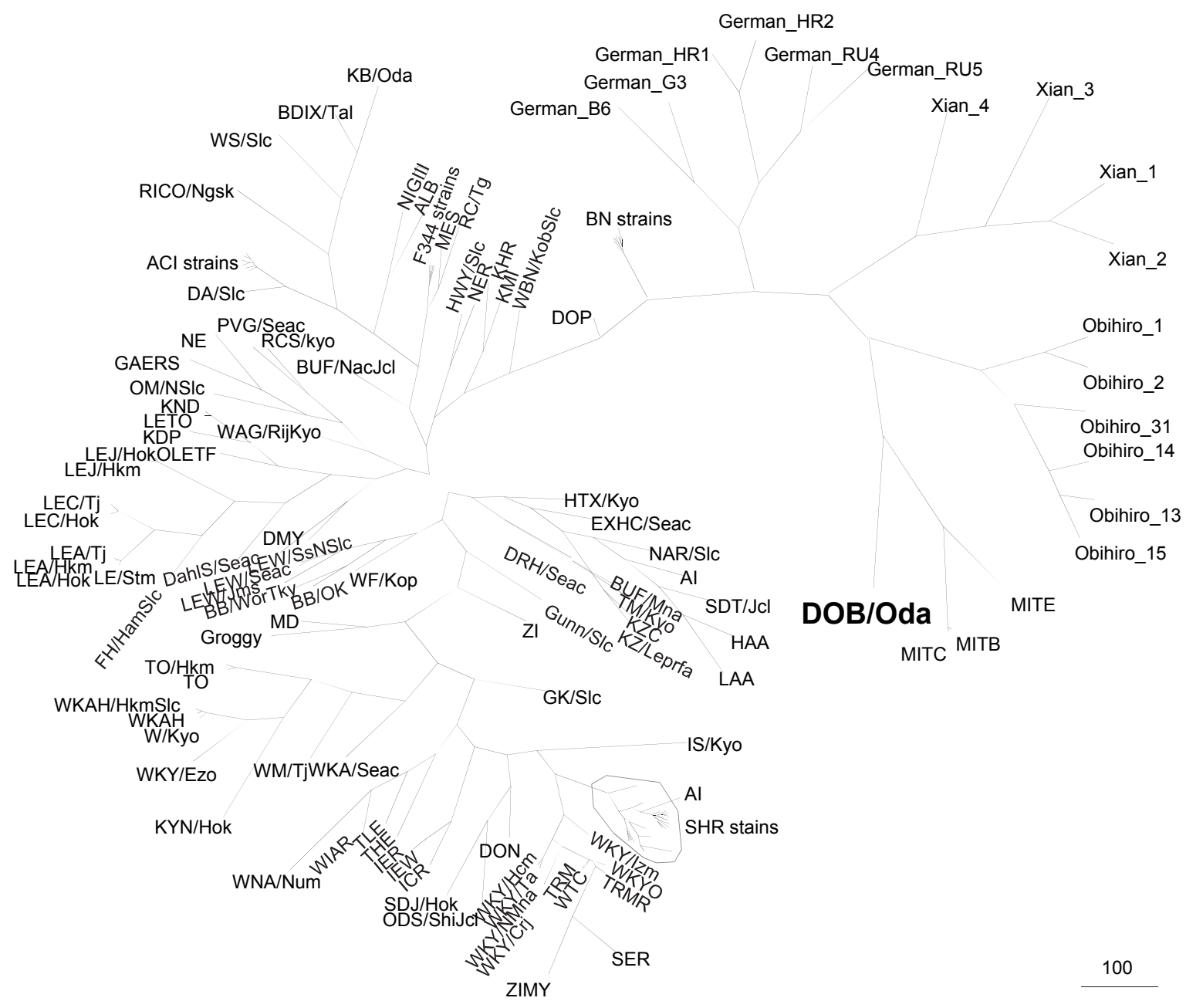

Fig. 2 